\title{
AVR Controlled Appliance Automation System Based on DTMF
}

\author{
Divyansh Agrawal \\ Department of Electronics and Telecommunication, Shri Shankaracharya Institute of Professional Management and \\ Technology (SSIPMT), Raipur, Chhattisgarh, India
}

\begin{abstract}
In modern house concepts, an integrating home automation system is now becoming a trend. This paper proposes a remote controlled automation system for the automation of home/industrial appliances. The prototype is composed of a remote section(transmitting) and a local section(receiving) each with a telephone/mobile. DTMF signalling, which is the standard dialling technique for telephone/mobile systems is used to transmit the signals to the local section from remote section. DTMF decoder at the local section decodes the DTMF signals and produces decoded output to the AVR-ATMega16A Microcontroller unit (Brain of the system) for further dedicated actions programmed in it and accordingly the Relay Logic circuit switch the appliances ON/OFF. With this prototype one can wirelessly automate home/industrial appliances and save electrical energy as well as labour, from far away locations. By monitoring and automating with this prototype one can also improve quality, accuracy and precision.
\end{abstract}

Keywords: AVR-ATMega16A Microcontroller, DTMF Signalling Tones, DTMF Decoder, Relay, Home Automation.

\section{INTRODUCTION}

Innovations and Inventions are mostly intended to bring ease and comfort to everyday life. Automation has become a trending and accepting technology in today's world. It is being preferred over manual systems. Globally, automation has become a necessity in every stream of work. Automating and remote controlling the home appliances is a sprouting concept with numerous benefits. With home automation one can add security to the house by just connecting the electric door locks to the prototype. Home automation and remote controlling contributes to the economy as on installing this prototype at home you make sure that you are only using the energy and resources that are necessary while you are at home. Efficient utilization of energy also saves money as it cuts down the electricity bill. Installing Home Automation system also increases convenience and comfort and offers peace of mind as one can remote control the appliances even when out of town or country through one's phone.

\section{SYSTEM REQUIREMENTS}

1. Major Hardware Requirements

- DTMF Decoder(IC MT-8870)

- AVR Microcontroller (here we are using ATMEL Atmega16a) controlling kit.

- AVR dude burner.

- Relays (5volt)

- Telephones/Mobile Phones

- Switching Appliances

2. Software requirements:

- WinAVR(programmers notepad)

- AVR studio

- Proteus ARES for PCB designing

- Proteus ISIS for simulation

- USBasp driver (for AVR dude burner)

\section{SYSTEM DESIGN}

The prototype uses Dual Tone Multi Frequency (DTMF) as the signalling technique. Dual-Tone Multi Frequency(DTMF) signalling is an in-band telecommunication signalling technique which uses voice frequency band 


\section{IJIREEICE \\ International Journal of Innovative Research in Electrical, Electronics, Instrumentation and Control Engineering \\ ISO 3297:2007 Certified \\ Vol. 5, Issue 4, April 2017}

over telephone lines/cellular network between telephone equipment/mobile and other communicating devices and switching centres. In telecommunication, a caller needs to dial the number of callee. Almost all landline and mobile handsets use pushbutton or touch keypads which generate DTMF keytones. DTMF is a signalling system for identifying the keys or the dialled numbers on pushbutton. With DTMF, each key when pressed on one's phone generates two tones of specific frequencies, one is the high frequency tone and other is the low frequency tone. The resultant tone is convolution of two frequencies.

Using mobile network which utilises DTMF signalling for remote controlling the home automation system is a reliable and resilient way as it is immune to interference from other radio sources and provides a very wide coverage.

Basically, there are two sections of the prototype:

1. Remote Section : Remote section is the transmitting or the wirelessly remote controlling section that generates the DTMF signals. Here, I have used a Mobile phone for this purpose.

2. Local Section : Local section is installed at the house to which the appliances are connected for automation and for remote controlling.

It comprises of :
a. Mobile Phone/GSM Module
b. DTMF decoding module
c. AVR-ATMega16A Microcontroller Kit board
d. Relay Logic Switching board
e. Appliances that has to be automated and remote controlled

DTMF decoding module is a very essential part of this prototype. It decodes the dual tones (key tones) generated on pressing the keypad at the remote section and produces 4-bits specific binary outputs for each pressed key tone. Decoding is done with a low power, MT8870 DTMF decoding IC embedded in this module. Fig. 1 illustrates the DTMF Decoding Module.

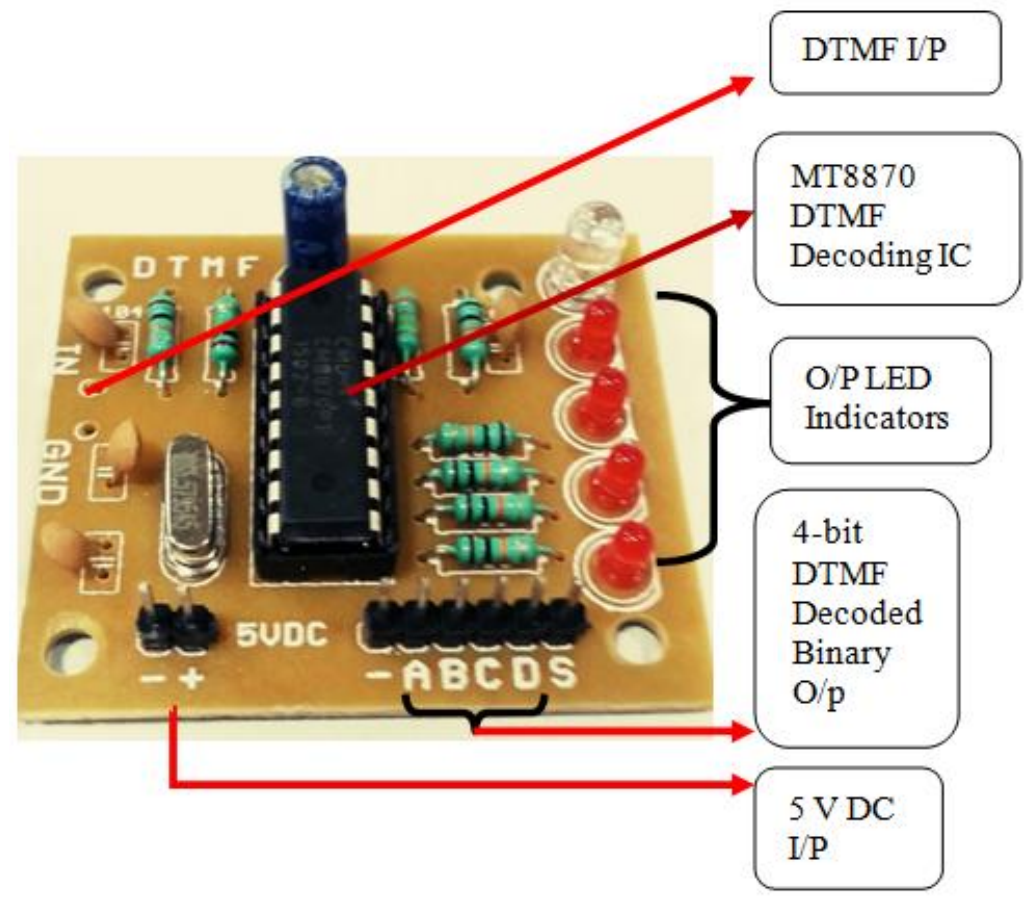

fig. 1 : DTMF Decoding Module

Decoded DTMF signals provide 4-bits binary output which is then passed on for processing to the Microcontroller Kit of the local section. Fig.2,shows the AVR ATMega16A Microcontroller Kit board with the program burnt in the microcontroller. Fig. 3 shows the PCB Layout of the microcontroller kit. 


\section{International Journal of Innovative Research in} Electrical, Electronics, Instrumentation and Control Engineering

ISO 3297:2007 Certified

Vol. 5, Issue 4, April 2017

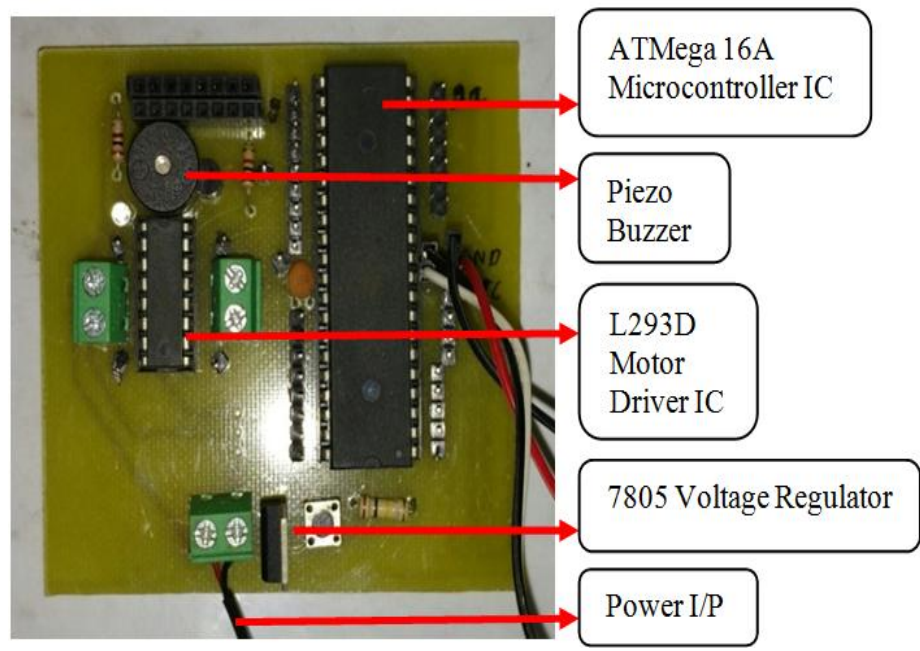

fig. 2 : AVR Microcontroller Kit

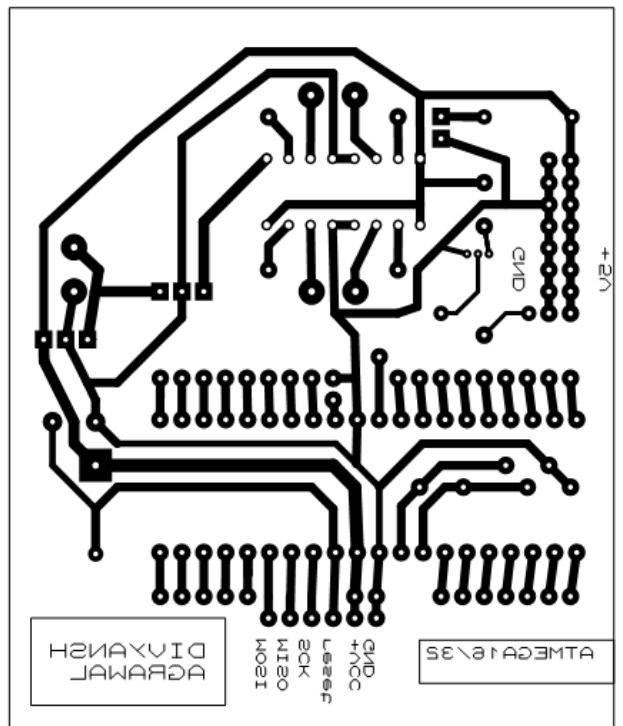

fig. 3 : AVR Microcontroller Kit PCB Layout

Fig. 4 shows the relay switching board which is responsible for the switching ON/OFF of the appliances. PCB Layout of the relay logic switching board is shown in fig. 5 .

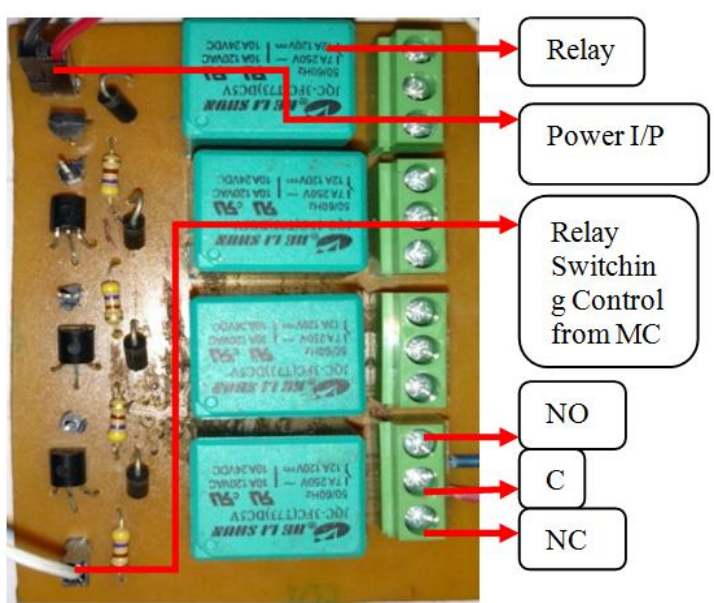

fig. 4 : Relay Logic Switching Board 


\section{International Journal of Innovative Research in Electrical, Electronics, Instrumentation and Control Engineering}

ISO 3297:2007 Certified

Vol. 5, Issue 4, April 2017

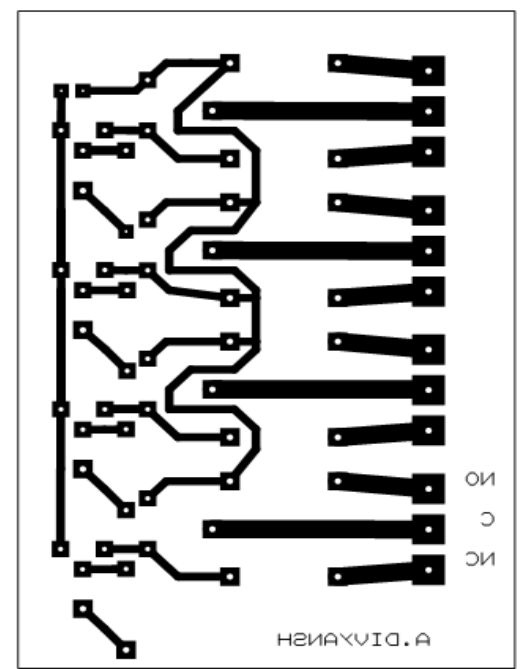

fig. 5 : Relay Logic Switching Board PCB Layout

IV.

METHEDOLOGY

The process of remote controlling and home automation from Remote section to the Local section follows :
A. DTMF Tone Generation
B. DTMF Detection
C. DTMF Decoding
D. Processing
E. Switching

\section{A. DTMF Tone Generation}

DTMF (Dual tone multi frequency) is generated by the superimposition of two sine wave tones. The row frequencies are the group of low frequencies and the column frequencies are the high group frequencies which combine to generate DTMF tones. This combination prevents the misinterpretation of the harmonics as both the group of frequencies have no harmonic relationship with each other. Fig. 6. illustrates the keypad that generates DTMF Tones with the combination of row and column frequencies. DTMF tone generation is done by establishing a voice call from mobile phone at the Remote Section to the mobile phone at the Local Section with DTMF tones active on the mobile phone at the Remote Section.

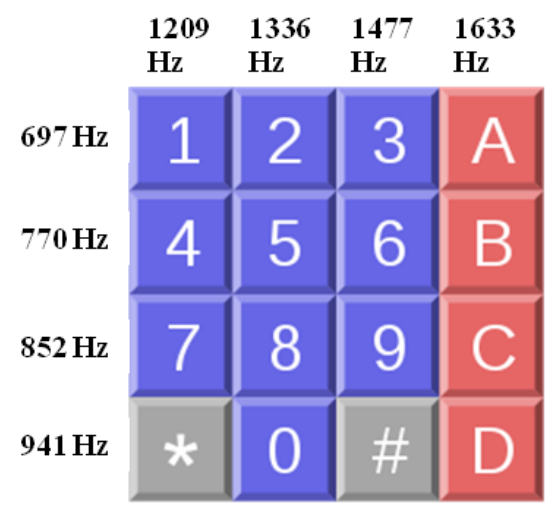

fig. 6 : DTMF Tone Generation

\section{B. DTMF Detection}

The task to detect DTMF tones in an incoming signal and convert them into actual digits is certainly more complex than the encoding process. The decoding process is by its nature a continuous process, meaning it needs to search an ongoing incoming data stream for the presence of DTMF tones continually[1]. Connecting the remote section and Local Section via mobile phones over mobile network makes the DTMF detection an ongoing process for the prototype. Goertzel algorithm is often used to detect the DTMF tones. 


\section{ISO 3297:2007 Certified}

Vol. 5, Issue 4, April 2017

\section{DTMF Decoding}

After the Remote Section is connected to the Local Section the DTMF signals sent by the Remote section needs to be decoded. The received audio signals at the Local Section are then passed from the mobile phone to the DTMF Decoding Module via 3.5mm Auxiliary cable. The DTMF Decoding Module has MT8870 decoding IC which decodes the dual tones and give a 4-bits binary output. Table 1 from [2] shows the functional decode table.

\begin{tabular}{|c|c|c|c|c|c|c|c|}
\hline Digit & TOE & INH & ESt & $\mathrm{Q}_{4}$ & $\mathrm{Q}_{3}$ & $\mathrm{Q}_{2}$ & $\mathrm{Q}_{1}$ \\
\hline ANY & $\mathrm{L}$ & $\mathrm{X}$ & $\mathrm{H}$ & $\mathrm{Z}$ & $\mathrm{Z}$ & $\mathrm{Z}$ & $\mathrm{Z}$ \\
\hline 1 & $\mathrm{H}$ & $\mathrm{X}$ & $\mathrm{H}$ & 0 & 0 & 0 & 1 \\
\hline 2 & $\mathrm{H}$ & $\mathrm{X}$ & $\mathrm{H}$ & 0 & 0 & 1 & 0 \\
\hline 3 & $\mathrm{H}$ & $\mathrm{X}$ & $\mathrm{H}$ & 0 & 0 & 1 & 1 \\
\hline 4 & $\mathrm{H}$ & $\mathrm{X}$ & $\mathrm{H}$ & 0 & 1 & 0 & 0 \\
\hline 5 & $\mathrm{H}$ & $\mathrm{X}$ & $\mathrm{H}$ & 0 & 1 & 0 & 1 \\
\hline 6 & $\mathrm{H}$ & $\mathrm{X}$ & $\mathrm{H}$ & 0 & 1 & 1 & 0 \\
\hline 7 & $\mathrm{H}$ & $\mathrm{X}$ & $\mathrm{H}$ & 0 & 1 & 1 & 1 \\
\hline 8 & $\mathrm{H}$ & $\mathrm{X}$ & $\mathrm{H}$ & 1 & 0 & 0 & 0 \\
\hline 9 & $\mathrm{H}$ & $\mathrm{X}$ & $\mathrm{H}$ & 1 & 0 & 0 & 1 \\
\hline 0 & $\mathrm{H}$ & $\mathrm{X}$ & $\mathrm{H}$ & 1 & 0 & 1 & 0 \\
\hline${ }^{*}$ & $\mathrm{H}$ & $\mathrm{X}$ & $\mathrm{H}$ & 1 & 0 & 1 & 1 \\
\hline \# & $\mathrm{H}$ & $\mathrm{X}$ & $\mathrm{H}$ & 1 & 1 & 0 & 0 \\
\hline $\mathrm{A}$ & $\mathrm{H}$ & $\mathrm{L}$ & $\mathrm{H}$ & 1 & 1 & 0 & 1 \\
\hline $\mathrm{B}$ & $\mathrm{H}$ & $\mathrm{L}$ & $\mathrm{H}$ & 1 & 1 & 1 & 0 \\
\hline $\mathrm{C}$ & $\mathrm{H}$ & $\mathrm{L}$ & $\mathrm{H}$ & 1 & 1 & 1 & 1 \\
\hline $\mathrm{D}$ & $\mathrm{H}$ & $\mathrm{L}$ & $\mathrm{H}$ & 0 & 0 & 0 & 0 \\
\hline $\mathrm{A}$ & $\mathrm{H}$ & $\mathrm{H}$ & $\mathrm{L}$ & \multicolumn{7}{|c|}{0} \\
\hline $\mathrm{B}$ & $\mathrm{H}$ & $\mathrm{H}$ & $\mathrm{L}$ & undetected, the output code \\
will remain the same as the \\
previous detected code
\end{tabular}

Table 1 - Functional Decode Table $\mathrm{L}=\mathrm{LOGIC}$ LOW, H=LOGIC HIGH, Z=HIGH IMPEDANCE
$\mathrm{X}=$ DON $T^{\top}$ CARE

\section{Processing}

The decoded 4-bits output from the DTMF Decoding Module needs to be processed for dedicated switching ON and OFF of the appliances. For processing, the decoded 4-bits output is simultaneously fed to the Microcontroller Kit board with an Atmel's AVR-ATMega16a Microcontroller IC. A program with a set of commands is burnt to the microcontroller with the help of AVR-Dude Burner. The microcontroller processes the 4-bits input and gives output at the pins according to the burnt code.

\section{E. Switching}

Relay is an electromechanical switch with an electromagnet and a set of contacts. The contact is mechanically switched from one to another due to the induced magnetic field generated by the electrical input to the coil of the relay. The Relay Logic Switching Board is used for the switching ON and OFF of the appliances with a good input voltage sensitivity. The input to the relays are fed by the output pins from the Microcontroller Kit Board. In this prototype, I have used 5V Relays. The relays switch to Normally Closed(NC) state when they receive low logic from the microcontroller and switch to Normally Open(NO) state on receiving high logic. The Common(C) of the relay is connected to power supply which powers the appliance connected to that relay. Hence, from the Remote section one can control the switching ON and OFF of the appliances at the Local section. The entire process of remote controlling and automation of home appliances through the developed prototype using Mobile Phones, MT8870 DTMF Decoder, AVR microcontroller Atmel's ATMega16A as the processing unit, and a Relay Switching Board is shown in fig.7.

\section{CONCLUSION}

The prototype proposed is an AVR controlled appliance automation system which uses DTMF signalling technique which provides worldwide remote switching capability. The prototype expressed the stability, accuracy, and the reliability of the DTMF technology. The paper introduces a collaboration of AVR Microcontroller Kit Board, DTMF technology and Relay Switching Board for remote switching system in home automation. The prototype is thoroughly tested a number of times with different appliances. 


\section{International Journal of Innovative Research in} Electrical, Electronics, Instrumentation and Control Engineering

\section{ISO 3297:2007 Certified}

Vol. 5, Issue 4, April 2017

\section{FUTURE DEVELOPEMENTS}

With the evolving concept of Internet Of Things (IoT) and use of Android/ios Applications, home automation can be done by developing a dedicated Android/ios application for the prototype and make the home automation; app controlled and even controlled over internet. This would increase the initial cost of the prototype installation at home but will also improve the users interface.

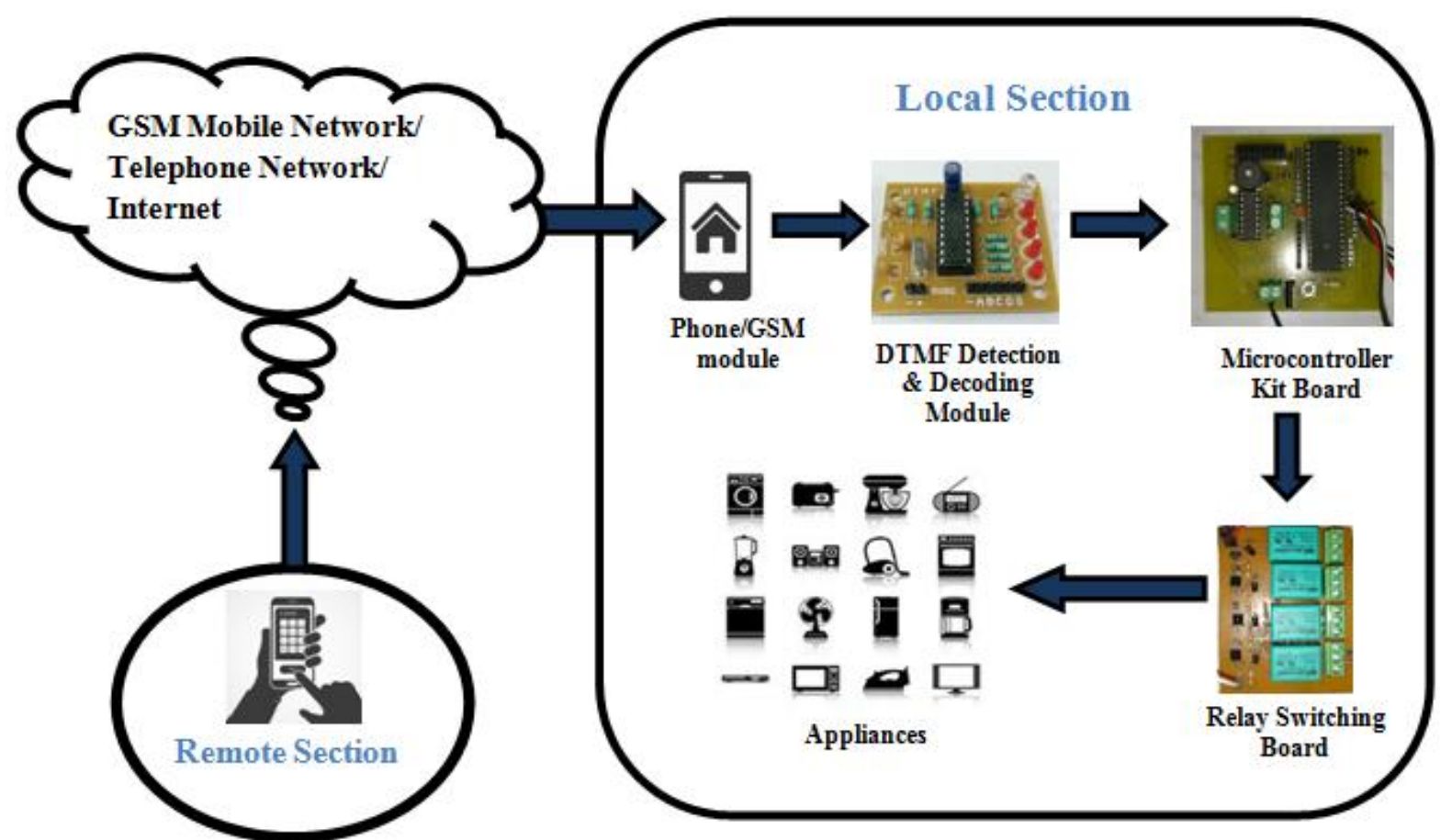

fig. 7 : Working of the prototype of AVR Controlled Appliance Automation System Based on DTMF

\section{REFERENCES}

[1] TEXAS INSTRUMENTS ,Application Report SPRA096A - May 2000 ," DTMF Tone Generation and Detection".

[2] ZARLINK Semiconductor, MT8870 IC Datasheet.

[3] Alyanna Rozel Cruz, Sarah Dyan Garraton, Joana Micah Jose, Alexis Malolos, Almira Panganiban, Rionel Belen Caldo ,"Model Case of Remote Switching Application System via Telephone Line Using DTMF",DLSU Research Congress Vol. 4,March 2016, ISSN $2449-3309$.

[4] Abdiweli Abdillahi Soufi and Abdirasoul Jabar Alzubaidi,"Remote Control System through Mobile and DTMF", International Journal of Computational Engineering Research, Vol.03, Issue 8, August 2013, ISSN 2250-3005.

[5] Mazidi , Naimi and Naimi , "AVR Microcontroller and Embedded Systems: Using Assembly and C ", first edition.

[6] George Kennedy, "Electronics communication system”, third edition McGraw-Hill Book Company.

[7] www.atmel.com

[8] www.nationalsemiconductor.com

[9] www.datasheetcatalog.com 